\title{
Instalasi Perpipaan Air Bersih Masjid Al-Ikhwan Rancagong Legok Tangerang
}

\author{
Yenni Arnas $^{1}$, Muh. Wildan ${ }^{2}$, KGS. M. Ismail ${ }^{3}$, Zulina Kurniawati ${ }^{4}$, Benny Kurnianto ${ }^{5}$ \\ 1,2,3,4,5 Politeknik Penerbangan Indonesia Curug \\ e-mail: ${ }^{1}$ yenni.arnas@ ppicurug.ac.id, ${ }^{2}$ muh.wildan@ ppicurug.ac.id, ${ }^{3}$ kgs.ismail@ppicurug.ac.id, \\ 4zulina.kurniawati@ppicurug.ac.id, ${ }^{5}$ benny.kurnianto@ppicurug.ac.id
}

\begin{abstract}
Abstrak
Air merupakan sumber utama dalam kehidupan, namun penyediaan oleh PDAM belum menjangkau ke seluruh masyarakat. Atas dasar hal ini maka masyarakat dalam penyediaan air diantaranya menggunakan air tanah dengan cara sedot mandiri oleh masing- masing rumah tangga, tempat ibadah, sarana umum, kantor swasta, kantor pemerintah dan lainnya. Berdasarkan hasil observasi yang dilakukan terhadap bangunan Masjid Al-Ikhwan Jl. Masjid RT 01 RW 08 Desa Rancagong Kecamaatn Legok Kabupaten Tangerang Provinsi Banten belum terdapat fasilitas sistem instalasi air bersih sehingga layak untuk dilakukan kegiatan pengabdian masyarakat di lokasi tersebut. Dalam kegiatan pengabdian kepada masyarakat ini melakukan beberapa hal yang akan menjadi solusi permasalahan fasilitas belum memenuhi standar, yaitu: melakukan pengeboran/pembuatan sumur yang akan menjadi sumber air bersih; melakukan perhitungan kebutuhan air bersih yang menjadi dasar untuk menentukan kapasitas dan jenis pompa, tempat penampungan air (dilengkapi dengan sensor pelampung sebagai media kontrol on/off pompa) dan sistem instalasi perpipaan air bersih yang akan berfungsi sebagai proses distribusi air bersih dari sumber kepada pengguna, sehingga mewujudkan system instalasi air bersih sesuai Standar Nasional Indonesia (SNI). Pelaksanaan kegiatan ini melibatkan dosen/instruktur sebagai wujud tridharma perguruan tinggi. Selain itu kegiatan ini juga melibatkan taruna/taruni sebagai media pembelajaran secara langsung di lapangan dan masyarakat yang dapat menambah pengetahuan tentang standar dari fasilitas bangunan.
\end{abstract}

Kata Kunci : air bersih, instalasi, pemipaan

\begin{abstract}
Water is essential for life, but not all people can access tap water. In fact, many people use ground water, which is not measured its purity, to supply household, places of worship, public facilities, private offices, government offices, and etc. This problem was also observed on Al-Ikhwan Mosque building Jl. Masjid RT 01 RW 08 Rancagong Village, Legok District, Tangerang Regency, Banten Province. In addition, in this place the water installation was not available. Therefore, it was feasible to carry out community service activities in that location regarding to clean water supply and installation. The method of this project were (1) drilling to make wells as clean water supply, (2) Calculating the need for clean water as the basis in determining the capacity and the type of water pump, (3) building water storage (equipped with a floating sensor as a control media turn the pump on or off automatically), and (4) piping to support distribution system of clean water from well to tap. This method was expected to meet Indonesian National Standard of clean water installation system. This project was supported by lecturers / instructors as their responsibility to practice Tridharma of higher education. Cadets/students was also involved in this project so they can demonstrate their knowledge about standard building facilities in society.
\end{abstract}

Keywords : clean water, instalation, piping 


\section{Pendahuluan}

Air merupakan sumber utama dalam kehidupan, namun penyediaan oleh PDAM belum menjangkau ke seluruh masyarakat. Atas dasar hal ini maka masyarakat dalam penyediaan air diantaranya menggunakan air tanah dengan cara sedot mandiri oleh masing rumah tangga, tempat ibadah, sarana umum, kantor swasta, kantor pemerintah dan lainnya.

Instalasi air bersih rumah tangga yang mandiri dengan sub sistim penyedotan, penampungan dan distribusi yakni menggunakan model instalasi air bersih sistim tertutup. Pada kenyataannya terdapat sub system dengan penyedotan dan pendistribusian (tanpa penampungan) dengan alasan tekanan keluarannya jauh lebih besar. Namun kondisi tersebut dari sisi pemakaian listrik dapat dihitung penggunaannya sebagai contoh ilustrasi sebuah rumah dengan pemanfaatan otomatisasi pompa air model pelampung tipe control level switch pada tandon air rata-rata membutuhkan air sebanyak 600 liter perhari dan pompa akan hidup minimal 2 hari sekali.

Musholla atau masjid sebagai salah satu kelompok pelaku sedot mandiri dan merupakan pengguna air 5 kali dalam sehari. Sehingga instalasi air bersih model sistim tertutup yang mandiri dengan sub sistim penyedotan, penampungan dan distribusi akan memberikan kenyamanan bersama akan ketersediaan air, tekanan keluaran cukup besar, hemat listrik, umur pompa dan lain sebagainya.

Mendasari hasil survey dan koordinasi yang kami lakukan dengan mitra yaitu belum tersedianya fasilitas system instalasi air bersih, sehingga perlu dan sangat diharapkan oleh mitra untuk bisa dipenuhi, yaitu: ketersediaan Sumber air bersih, tempat penampungan air bersih, instalasi perpipaan air bersih, ketersediaan tempat wudhu.

Berdasarkan analisis situasi yang telah diuraikan di atas, maka dapat dirumuskan permasalahannya meliputi: standar Perhitungan kebutuhan kapasitas dan jenis pompa, standar perhitungan kebutuhan kapsitas tempat penampungan air, standar penghitungan tekanan yang diinginkan, standar diameter pipa sedot, pipa masuk ke bak dan pipa keluaran, standar memasang instalasi air bersih, pememilihan model Pelampung Tipe Control Level Switch,pemilihan ukuran pompa, dan pememilihan tipe kran.

Berdasarkan latar belakang dan kondisi mitra masjid Al-Ikhwan -Legok , solusi yang ditawarkan untuk mengatasi masalah fasilitas air bersih di Masjid Al-Ikhwan Jl. Masjid RT 01 RW 08, Desa Rancagong Kecamatan Legok Kabupaten Tangerang Provinsi Banten adalah dengan melaksanakan kegiatan Pengadian kepada Masyarakat (PKM) yang bertujuan untuk menyelesaikan permasalahan mitra yaitu dengan menyediakan air bersih dan instalasi perpipaan.

Pada kegiatan pengabdian masyarakat kali ini, tim PKM prodi TMB melaksanakan kegiatan dalam beberapa tahap. Pembahasan perencanaan sistem penyediaam air (dikelas dan dilapangan) meliputi menghitung tekanan yang diinginkan, menentukan kapasitas dan jenis pompa, menentukan besaran diameter pipa sedot, pipa masuk ke bak dan pipa keluaran, memilih tandon air, memilih model pelampung tipe control level switch, memilih tipe kran.

Pelaksanaan kegiatan instalasi air bersih model sistem tertutup, pengeboran sumur, instalasi pompa (sementara), instalasi sumber listrik untuk pompa, penjernihan, instalasi pompa (tetap), instalasi perpipaan, instalasi tiang penyangga bak penampung air, instalasi bak tendon air, instalasi radar otomatis,

Selain itu, dalam model instalasi air bersih sistem tertutup juga diperlukan sosialisasi tentang perawatan, meliputi langkah analisa cepat ketika mesin pompa macet, cara menyetel otomatis pompa model konvensional, kenapa mesin pompa air harus dipancing, air sumur keruh dan lama tidak dipakai, mesin dynamo pompa tidak bias perputar, tanda pompa air masuk angin 
dan cara mengatasinya, mengatasi otomatis pompa air bunyi terus, pompa air hidup tidak keluar air, instalasi yang aman untuk memasang pompa air

Diharapkan dengan adanya kegiatan PKM ini maka kebutuhan akan air bersih bagi jamaah masjid Al-Ikhwan lebih mudah diperoleh dan tentunya bisa dimanfaatkan juga oleh masyarakat sekitar yang membutuhkan. Hal ini selaras dengan tujuan pelaksanaan pengabdian masyarakat yaitu mengimplementasikan hasil Pendidikan yang dapat dimanfaatkan oleh masyarakat.

\section{Metode}

Metode yang dilakukan dalam pelaksanaan kegitan terdiri atas beberapa tahapan. Pertama, tim melakukan survey lapangan terkait rencana pelaksanaan kegiatan Pengabdian kepada Masyarakat dengan untuk mendapatkan permasalahan mitra. Kedua, Tim internal melakukan koordinasi terkait hasil survey lapangan, untuk menentukan rencana kegiatan agar sesuai dengan permasalahan mitra. Ketiga, tim melakukan koordinasi lapangan terkait rencana pelaksanaan kegiatan Pengabdian kepada Masyarakat, dengan menyampaikan jenis, lingkup, tim dan waktu kegiatan/pekerjaan. Keempat, tim membuat proposal kegiatan pengabdian kepada masyarakat. Kelimat, tim menyerahkan proposal kegiatan pengabdian kepada masyarakat kepada Kepala Pusat Penelitian dan Pengabdian Masyarakat. Selanjutnya, tim melaksanaan kegiatan pengabdian kepada masyarakat. Tim kemudian membuat laporan hasil kegiatan pengabdian kepada masyarakat. Terakhir, tim menyerahkan laporan kegiatan pengabdian kepada masyarakat kepada Kepala Pusat Penelitian dan Pengabdian Masyarakat.

Untuk menunjang kelancaran kegiatan, tim pengadi juga melakukan pendekatan masalah mitra dengan beberapa cara. Tim melakukan survey lapangan untuk melihat langsung kondisi yang ada. Permasalahan - permasalahan yang ada dilapangan kemudia dicatat. Rincian rencana kegiatan yang meliputi lingkup, tim dan waktu kegiatan/pekerjaan disampaikan ke masyarakat.

Kegiatan pengabdian masyarakat juga membutuhkan partisipasi mitra dalam pelaksanaan program yang dilakukan dengan beberapa Langkah. Mitra memberikan masukan terhadap lingkup pekerjaan yang akan dilakukan. Mitra juga memberikan informasi data lapangan seperti, luas bangunan dan fungsi ruang. Tim pengabdi dan mitra menyesuaikan kegiatan rutin lokasi dengan rencana kegiatan pengabdian kepada masyarakat. Mitra juga menyatakan kesediaan untuk ikut terlibat pada saat pelaksanaan kegiatan pengabdian kepada masyarakat untuk personil dalam hal tenaga bantuan dan proses evaluasi terhadap pekerjaan yang dilakukan.

Langkah terakhir dalam pelaksanaan kegitan pengabdian ini adalah evaluasi pada setiap tahapan. Proses evaluasi terhadap proses pelaksanaan program dilakukan oleh tim pengusul dan personil mitra. Proses evaluasi dilakukan terhadap bahan atau alat yang digunakan pada saat pekerjaan. Proses evaluasi pada akhir dilaksankan pada setiap pekerjaan yang dilakukan. Tim pengabdi menyampaikan sistem hasil pekerjaan setelah selesai program. Tim menyampaikan hal-hal yang perlu dilakukan untuk proses pemeliharaan atau perbaikan. Tim pengabdi dan mitra menyatakan kesediaan tetap menjalin komunikasi, jika terdapat hal-hal yang diperlukan terhadap hasil program. Tim dan mitra menyampaikan program kegiatan pengabdian kepada masyarakat yang mungkin dapat dilakukan untuk periode berikutnya.

\section{Hasil dan Pembahasan}

Tahap pertama kegiatan adalah rapat persiapan internal yang melibatkan tim pelaksana PKM dan pengurus masjid Al-Ikhwan, adapun materi yang dibahas adalah meliputi 
pembahasan lingkup pekerjaan, pembahasan pembukaan PKM, pembagian tugas sebagai penangung jawab kegiatan PKM, dan pembahasan tahapan dan waktu pelaksanaan kegiatan PKM.

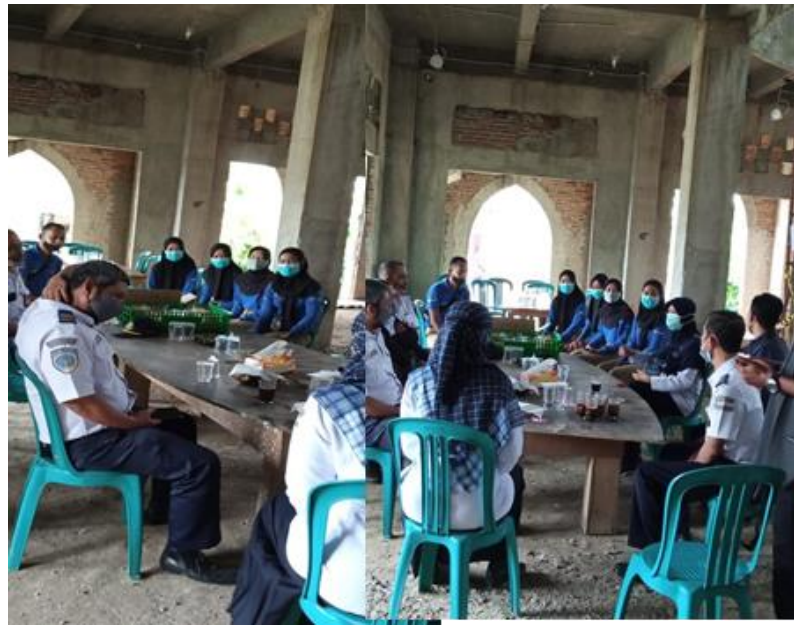

Gambar 1. Rapat dengan pengurus masjid Al-Ikhwan

Pada tahap kedua pelaksanaan kegiatan PKM, tukang melanjutkan proses penggalian/pembuatan sumur. Untuk mendapatkan sumber air yang bagus, maka penggalian sumur dilakukan sampai mencapai tingkat kedalaman air dengan kedalaman sampai dengan 20 meter. Selanjutnya dilaksanakan persiapan pembuatan instalasi perpipaan air bersih. Dalam pembuatan tower penampungan air, karena membutuhkan waktu sehingga tower air ini sudah dibuat sebelum kegiatan agar bisa dipasang tepat waktu.

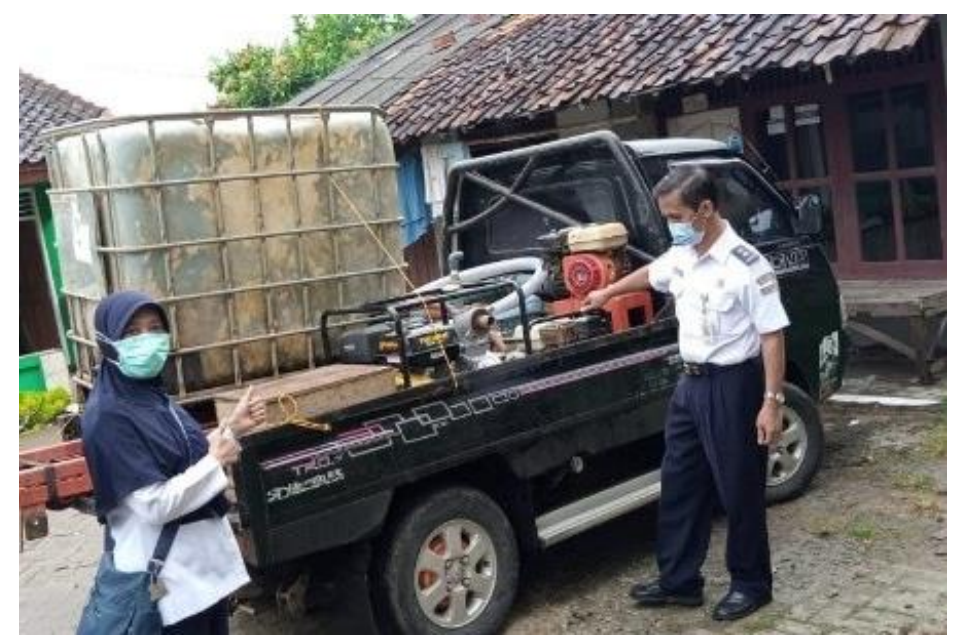

Gambar 2. Pelaksanaan pengeboran

Selanjutnya pekerjaan yang dilakukan adalah pemasangan tower penampungan air . Pekerjaan diawali dengan pembuatan pondasi, dilanjutkan dengan pemasangan tower penampungan. Setelah tower penampungan air selesai dipasang, maka selanjutnya adalah pemasangan bak penampungan dengan kapasitas 550 liter dan instalasi perpipaan air yang akan dikerjakan pada keesokan harinya.

Pada tahap ketiga, pekerjaan dilanjutkan dengan pemasangan instalasi perpipaan. Pada kegiatan ini tim PKM juga melibatkan taruna-taruni sebagai proses pembelajaran secara langsung terutama untuk materi Water Pumping System. Selain proses pemasangan instalasi , pekerjaan awal untuk pembuatan pondasi tempat wudhu juga mulai dikerjakan. 


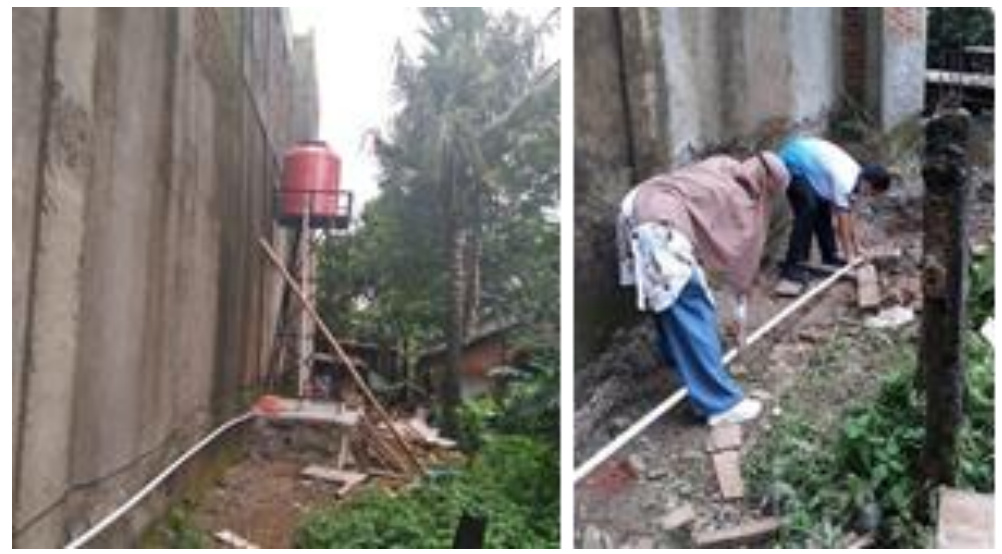

Gambar 3. Pemasangan instalasi perpipaan air bersih

Di tahap kempat dilaksanakan pekerjaan lanjutan pembuatan tempat wudhu. Sesuai dengan hasil kesepakatan pada saat rapat dengan pengurus masjid, maka untuk keran tempat wudhu dibuat sebanyak 8 (delapan) titik. Untuk posisi lantai tempat wudhu juga dibuat lebih tinggi dari jalan dan dibuat batas pada pinggirannya.

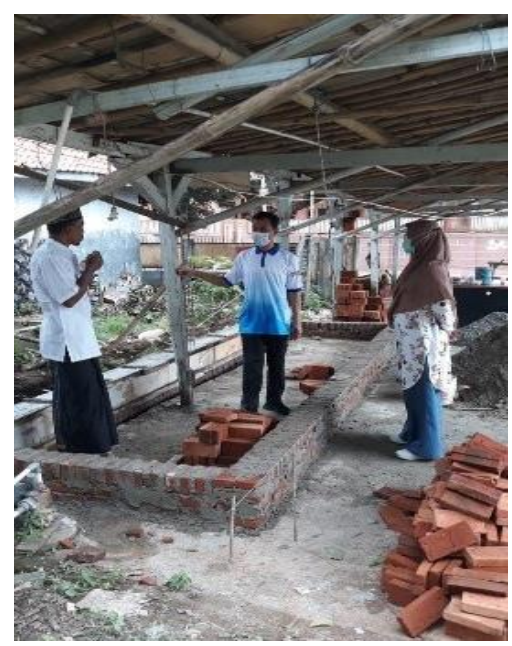

Gambar 4. pemasangan pondasi tempat wudhu

Pada tahap kelima, kegiatan PKM diakhiri dengan melakukan pemasangan keramik pada dinding dan lantai tempat wudhu. Pemasangan membutuhkan waktu satu hari penuh. Pekerjaan ini dilakukan oleh para tukang yang membantu kegiatan tim PKM selama kegiatan berlangsung.

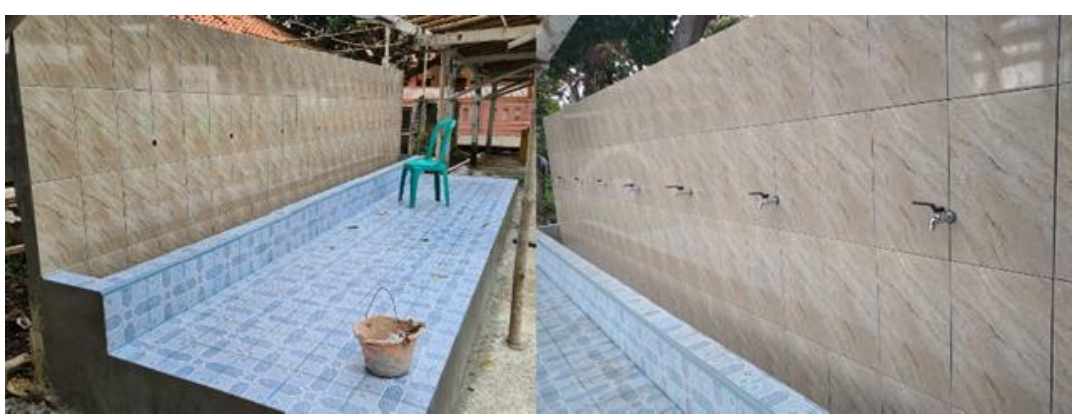

Gambar 5. Tempat wudhu yang sudah dikeramik 


\section{Kesimpulan}

Selesainya kegiatan Pengabdian Kepada Masyarakat ini memberikan beberapa hasil kesimpulan. Pertama, Masjid mempunyai sumur yang diharapkan tidak akan kering pada musim kemarau. Masjid mempunyai ketersediaan air bersih dengan penampungan air yang dilengkapi dengan system otomatis untuk pompa. Instalasi perpipaan saluran air bersih terpasang pada masjid. Fasilitas tempat wudhu yang memadai sudah tersedia di masjid

Dengan melihat masih adanya tempat-tempat disekitar PPIC, baik masjid, pesantren atau sekolah-sekolah yang mempunyai fasilitas jauh dari layak atau tidak sesuai dengan standar seharusnya, perguruan tinggi diharapkan untuk lebih peduli dengan turut melakukan kemitraan dalam kegiatan Pengabdian Kepada Masyarakat. Untuk memenuhi kewajiban Tridharma Perguruan Tinggi, PPIC diharapkan memiliki kesiapan pengajuan anggaran untuk kegiatan Pengabdian Kepada Masyarakat berupa penyediaan air bersih.

\section{Daftar Pustaka}

Modul Pembelajaran Water Pumping System, Prodi Teknik Mekanikal Bandar Udara, Politeknik Penerbangan Indonesia Curug

P. Van. Harten dan Ir. E. Setiawan, Instalasi Listrik Arus Kuat Jilid 2, Jakarta, Bina Cipta, 2019

P. Van. Harten dan Ir. E. Setiawan, Instalasi Listrik Arus Kuat Jilid 3, Jakarta, Bina Cipta, 2019

Rishel, James. (20202), Water Pumps and Pumping System. New York, USA; Mac Graw Hill

Sularso Haruo Tahara, Pompa dan Kompresor, Pemilihan, Pemakaian dan Pemeliharaan

Tata Cara Perencanaan Sistem Plambing (2005), SNI 03-7065-2005. Jakarta ; Badan Standarisasi Nasional 